\title{
Multiple symptomical analysis of fails in the EGR system of HDI engine
}

The article presents the process of fault location in the HDR-rhr engine EGR system based on the characteristics obtained in the conditions of traction measurements using the ESI Tronic 2.0 program. The measurements were obtained using the licensed BOSCH KTS540 diagnostic tester. In the process of diagnostic inference the PWM signal coefficient has been analyzed in relation to the level of boost pressure, mass variability and air temperature in the intake system (based on MAF data) and EGR valve positioning for variable angular positions of the accelerator pedal. Analysis of the characteristics allowed for proper identification of faults previously stored in the system with OBDII error codes. Attention was paid to the issue of sediment formation in the EGR valve channels as a result of using diesel oil with the participation of biocomponents. Sludge analysis was carried out in a certified laboratory using infrared spectroscopy methods. Conclusions have been drawn for the presence of non-oxidized components of organic origin precipitated in the channels of the EGR system.

Key words: EGR exhaust gas recirculation valve, fluorescence, IR infrared spectroscopy, biocomponents

\section{Introduction}

The high degree of sophistication of the functional systems of the engine introduces the possibility of various types of damage and errors in the control system. Diagnostic procedures OBDII (On-Board Diagnostic level 2) allow locating faults and checking components in the state mounted in the vehicle, also providing data on the type of equipment fitted, software version and drivers used. Thanks to this, you can get data showing the cause of the failure of a given system in the car. In addition, diagnostic programs give the possibility of taking real-time measurements of selected parameters for such systems as, for example: HPCR, EGR, DPF. The OBD II system (EOBD) is a set of diagnostic tests and calculation, decision and real-time procedures. OBDII standards determine which systems in the vehicle are to be supervised, each controller demonstrating the implementation of at least one control procedure creating continuous or discontinuous monitors. The diagnostic monitor contains diagnostic procedures responsible for the control and observation of the components assigned to it. Engine manufacturers are required to publish an algorithm allowing to implement the driving cycle that guarantees the performance of all monitors provided for in the OBDII standard [9]. The ability of multi-symtomics inference and knowledge of technical solutions used in vehicle systems are the basis for shaping accurate diagnostic decisions. Identification of a multi-symptom engine fault with CS is usually a problem even for a diagnostician using dedicated testers. Detection of a fault in advanced vehicle structures requires from the diagnostician considerable knowledge in the scope of construction and functioning of mechatronic systems.

The EGR (Exhaust Gas Recirculation) exhaust gas recirculation system, which is often used in engines with low displacement, is often used to reduce the combustion speed in the explosive phase, thus contributing to the reduction of $\mathrm{NO}_{\mathrm{x}}$ in the exhaust. However, an excessive share of exhaust gases in the entire charge delivered to the cylinder may cause a decrease in power and a significant increase in PM emissions, thus obtaining unfavorable values of other engine work indicators [2]. Limit value of the PM particulate emission (Particulate Matter) is an equivalent criterion in relation to the emission of toxic exhaust components in SI engines [4]. These particles absorb heavy metals, sulfur and nitrogen compounds as well as polycyclic aromatic hydrocarbons, among which may be directly or directly carcinogenic substances [10].

\section{Diagnostic technologies and procedures}

The diagnostic testers used on the car services are terminals connected to the car's producer's servers, carrying out the diagnosis process in the Pass-Thru system. Professional diagnostic devices of such companies as Bosch, Hella-Gutmann, Texa, Delphi, Magnetti Marelli - also allow independent car services to connect to manufacturers' servers, download diagnostic and service data, update driver software, encode functions. Scanners of many companies are offered on the market, most of which carry out tests based on the ELM327 chip. The popular ones include scanners operating according to USB, Bluetooth and WiFi technology. USB scanners use PCMSCAN, Dash Command, ScanXL software with access to a Windows PC or Mac OSX and Linux. Scanner with Bluetooth technology works with Android, Symbian, Windows Phonem. It is also possible to use a $\mathrm{PC}$ with a Bluetooth receiver, but the collision takes place with a different iPhon protocol. Free applications from the Internet are available to read and delete errors, and control current parameters for selected drivers. information is appearing more and more often about the possibility of taking over such applications to controlling selected functions of the vehicle. Scanners create their own WiFi network function with iPhones using application Dash Command, OBD Doctor, OBD Fusion as well as Android phones.

Car manufacturers use their own error determination terminology. Particular diagnostic testers can read errors in various ways, the coding of which does not comply with ISO standards. In this way, it may happen that the same error will be read in different ways by particular diagnostic testers [14]. The basic disadvantage of universal diagnostic testers is the inability to control all possible parameters, while the error coding is general and inaccurate, which 
makes it difficult to indicate the fault. The advantage of the KTS series testers is the ESI Tronic software that provides extensive service information containing technical and repair data. High-tech testers enable to perform activation tests of executive elements, adaptation of controllers consisting in restoring factory settings, entering codes necessary to run executive elements. In addition, real-time parameter recorders of the motor operation are used as a function of time and are connected to the vehicle's diagnostic connector to diagnose occasional faults. It is possible to read and interpret the saved values in graphical form.

Despite advanced diagnostic technologies, determining the cause of the fault in the EGR system is problematic. The problem arises from determining the mass of recirculated gases as the difference in mass of the load and air mass in relation to the temperature correction of the intake air. In this case, the recognition of errors is a complex procedure, since a group of mutually coupled signals from the electric actuator of the system is analyzed, in relation to the mass flow signal, intake pressure, temperature factors and shaft speed [8]. The degree of EGR valve opening determines the exhaust mass for the purpose of ensuring the instantaneous value of the recirculation degree XEGR. The error interval is strictly set and the exceeding of this value determines the emission fault leading to the signaling of the engine operation status via the MIL indicator. The effects of these processes result in the occurrence of engine failures related to the record in the error code controller, the MIL indicator signaling, and switching to the engine's substitute operating characteristics.

The main problem is the inability to measure the specific heat of recirculated gases based on the specific heat of its individual components with the determination of their mass shares. There is also a variable heat exchange surface, differentiated heat transfer coefficient by the material structure of the intake manifold and a variable heat exchange time at the charge and ambient temperature difference. It is necessary to average the flow conditions of the factor with variable channel geometry in zones with different wall temperatures. Is important the lack of possibility to measure the mass flow rate of recirculated gases at variable temperature of the medium at the inlet to the cylinder.

The EGR system is distinguished by the degree of a significant tolerance range to momentary change in the recirculation rate, especially in the in the range of unsteady of transient engine loads. In addition, as a result of the use of biofuel additives, there is a differentiated, relative to hydrocarbon fuels, share in the exhaust of such components as: $\mathrm{CO}_{2}, \mathrm{CO}, \mathrm{HC}, \mathrm{NO}_{\mathrm{x}}[12]$.

\section{Object of diagnostic tests}

The object of diagnostic tests was engine the $2.0 \mathrm{HDi}$ RHR with self-ignition, showing uneven idling. During the increase of the angle of the accelerator pedal, the engine went out, which indicated the emergency operation status, also signaled by the MIL indicator. Typical symptoms of uneven engine operation and power drop along with signaling of the MIL (Malfunction Indicator Light) indicator may have various causes [13]. Normally, the error codes indicate a fault in the fuel injection system, a fault in the
VTG turbocharging system or determine the condition of the EGR valve malfunction.

The car diagnostics process was performed in stationary conditions with the LEXIA 3 FULL CHIP diagnostic interface with the Peugeot Planet PP2000 software. The set works with the latest versions of Lexia, Proxia, Diagbox and Peugeot Planet programs. The stored code of the first error P0490 indicates a malfunction of the EGR due to incorrect positioning of the valve work piece in relation to the reference value. The next code P0401 referred to the erroneous values of flow air intensity as indicated by MAF. The main problem of identifying the damage resulted from the stored P1471 code during reading with the engine switched off, passing periodically in the transient error during the test on the running engine. The Diagbox intervention periodically eliminated the saved error code, which, however, returned again, especially after the dynamic acceleration of the vehicle as part of the traction test. Usually, the periodic failure may be related to the intervention made to remove sediments from the DPF system or VGT turbocharger or it results from their replacement of components without removing the previous data from the EDC controller [5]. Lack of software "adaptation" performed at a coolant temperature above $70^{\circ} \mathrm{C}$ may also cause transient errors. Periodically, the P0406 code is written which refers to the incorrect positioning of the electrically controlled EGR valve at too high control signal voltage.

In the first place, as a result of the test, correctness of basic work parameters was confirmed, including: the output pressure of the fuel pump (26 MPa at the crankshaft rev. $6801 / \mathrm{min}$ ) and the correct synchronization of the camshaft with crankshaft. The actual positioning of the EGR valve shows a small real difference $(51.8 \%$ ) in the ratio of the set point $(52.1 \%)$ with a fill factor of $52 \%$. However, there is a significant difference between the set value has a low value of the boost pressure $(970 \mathrm{mbar})$ in relation to the required one (1010 mbar). The mass air flow value and the air temperature sensor data from the MAF flowmeter in the intake system were checked. At $12^{\circ} \mathrm{C}$, the actual $(455 \mathrm{mg})$ and required $(610 \mathrm{mg})$ values differed excessively, which in the first place determines the defect of the flowmeter suggested by the saved error code P0401.

The initial stages of the engine diagnostic process carried out in stationary tests with indication of probable damages to both the EGR and MAF systems required extending the interpretation of the operating states of the engine's functional systems by additional records of the actual parameter values during the traction test.

As indicated in code P0401, replacing the MAF flowmeter would lead to a slight improvement in the exploitation of the engine. Therefore, it is necessary to aim for a full picture of the operating parameters of the interdependent systems and not individual symptoms or to replace the elements according to the error codes record [3].

Therefore, traction tests were performed with the actual engine parameters saved by the BOSCH KTS 540 diagnostic tester with the ESI (Tronic) 2.0 program. The actual values of the required and measured boost pressure, positioning of the EGR valve, engine speed and driving speed were obtained (Fig. 1). The record of error codes showed, 
in addition to $\mathrm{P} 0490$, an additional code P0102 regarding the signal from the MAF flowmeter. The test clearly indicated a failure of the EGR valve as a result of incorrect positioning of its moving elements, which caused an excessive participation of exhaust gas recirculation and a reduction of the mass air flow rate. A list of saved error codes during the test under stationary conditions and traction test is given on the Table 1 .

Table 1. Record of error codes during the test under stationary conditions and traction test

\begin{tabular}{|l|c|c|}
\hline $\begin{array}{l}\text { error } \\
\text { code }\end{array}$ & description & Tester \\
\hline P0490 & $\begin{array}{c}\text { Signal of electrical position of EGR valve: } \\
\text { Positive loop deviation }\end{array}$ & $\begin{array}{c}\text { PP2000 } \\
\text { KTS 540 }\end{array}$ \\
\hline P0401 & $\begin{array}{c}\text { Fault in the air circuit in the power supply } \\
\text { system }\end{array}$ & PP2000 \\
\hline P1471 & $\begin{array}{c}\text { Throttle control electromagnetic valve (EGR): } \\
\text { open throttle }\end{array}$ & PP2000 \\
\hline P0102 & $\begin{array}{c}\text { Flowmeter signal; measured expenditure is } \\
\text { smaller than the minimum expenditure }\end{array}$ & KTS 540 \\
\hline
\end{tabular}

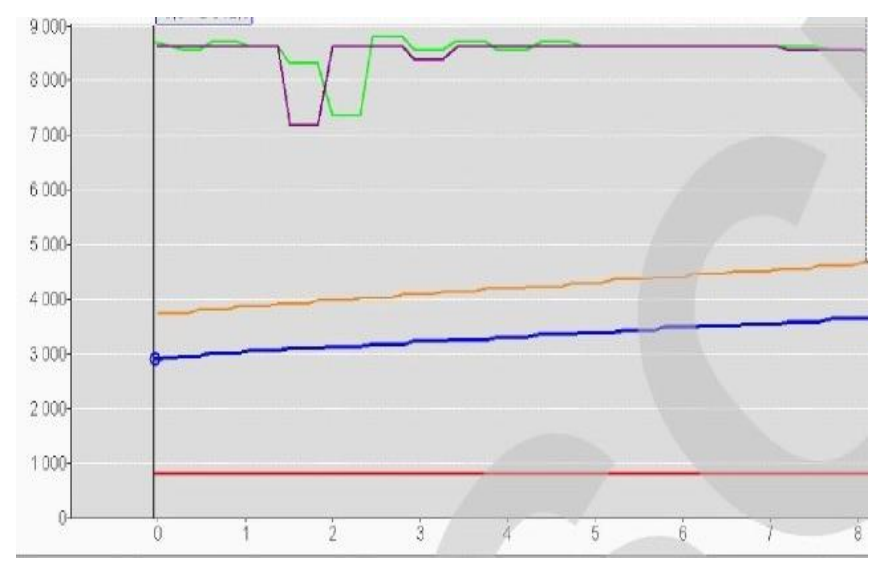

Fig. 1. Record of real parameters during the test as a function of time (s) Markings: boost pressure required - purple line, boost pressure measured green line, travel speed - yellow line and engine speed - blue line (max. Test $102 \mathrm{~km} / \mathrm{h}$ at $23001 / \mathrm{min}$ ), red line - EGR valve positioning

Re-test traction was, after replacing the complete EGR valve, showed the correct flow characteristics of the actual boost pressure (green line) in relation to the required one (violet line). There is only a small shift (about $0.5 \mathrm{~s}$ ), resulting from the inertia of the VGT turbocharger (for a normative pressure over 2300 mbar) when increasing the speed with the EGR valve closed confirmation of the accuracy of the diagnostic process is the recording of the actual parameters within the traction test phases (Fig. 2):

- acceleration phase with change of gear (ca. $20 \mathrm{~s}$ ),

- phase of maintaining a constant speed of ride (min. $5 \mathrm{~s}$ ),

- phase of releasing idling (ca. $20 \mathrm{~s}$ ),

- engine braking phase (ca. $15 \mathrm{~s}$ ).

In the acceleration phase of the car, the proper functioning of the EGR valve can be observed, indicating significant modulations of the exhaust gas recirculation rate. While maintaining a constant car speed, the exhaust gas recirculation rate is maintained at around $40-60 \%$, for the idling phase and during engine braking it reaches $70-80 \%$.

The main cause of the fault leading to the damage of the EGR valve turned out to be an excessive PM deposit in the zone of channels and mushroom valve in the EGR system.
Attempts at mechanical and chemical cleaning (hexane) of the stem and valve seat areas have not produced any results. Initial control of the basic engine parameters showed a good diagnosis. The last step is to delete errors saved in the controller's memory. This is an action that should always be done after repair or replacement of damaged elements [13].

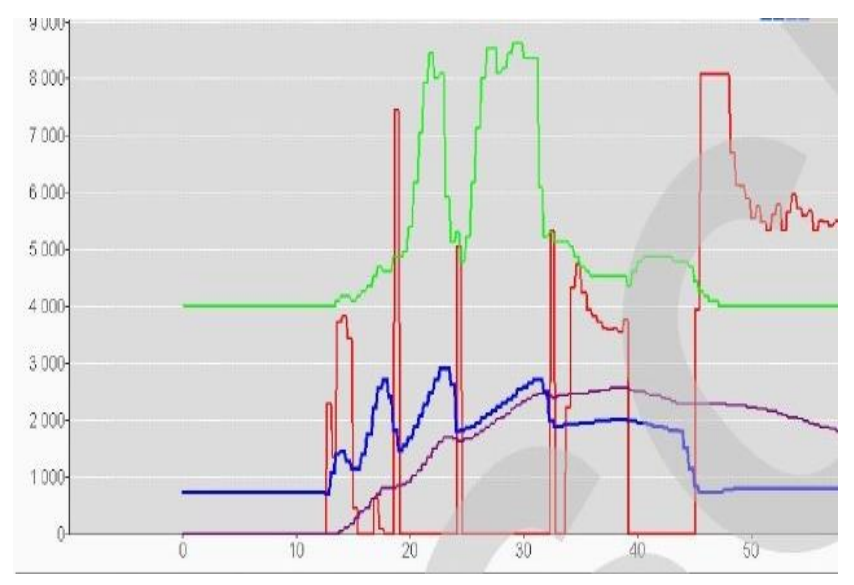

Fig. 2. Record of real parameters during traction test as a function of time (s). Markings: engine speed - blue line, fill factor for the exhaust gas recirculation valve (recirculation level) - red line, boost pressure - green line, car speed - purple line

\section{Spectral analysis of sediments in the exhaust gas flow zones}

The supplementation of diagnostic methods beyond the scope of EOBDII tests is the indication of various aspects expressing the causes of the failures. The inevitable consequence of fuel combustion in piston engines are IDID (Internal Diesel Injector Deposits) deposits created on work elements, causing a number of negative effects: deterioration of starting capacity, power drop, increased fuel consumption, increased emission of toxic exhaust components [6]. The functioning of HPCR, DPF, SCR and EGR systems in the SI engine depends to a large extent on meeting the fuel quality criteria included in the "Fuel Requirements for Diesel Fuel Injection Systems Diesel Fuel Injection Equipment Manufacturers Common Position Statement 2009" and the provisions contained in the World Card Fuels for category 4 diesel [7]. In the case of compressionignition engines with direct fuel injection, the quality of fuel determines the speed of destruction of functional systems which is conditioned by the composition of fuel, fatty acid residue, a package of enriching additives and solid impurities. The type and physicochemical properties of the fuel (viscosity, density, fractional composition, cetane number, lubricity) and operating conditions of the selfignition engine - significantly affect the mechanism of sediment formation. The results of many research works [1, $3,6]$ indicate the complexity of the sediment formation process depending on the content of metal salts in diesel fuel containing FAME or ashless polymeric materials. Gas oils in the commercial distribution may contain various acid components (unsaturated fatty acids) with a lubricating additive character, which may favour the formation of sediments due to the acidic impurities contained therein and the presence of metal ions. Overlapping deposits in the 
EGR valve duct zone are difficult to remove, as shown in Fig. 3, as a comparison of two valve seat images in the state of the saved error code and after partial cleaning with carbon dioxide removal agents. The macrostructure of the sediments in the microscopic image on the external surface of the mushroom EGR valve is presented on the Fig. 4. Similarly, hard-to-remove deposits and traces of seizure of the pin of the mushroom EGR valve were observed in the cooperation zone with the guide sleeve (Fig. 5). Improvement of the functional status of the EGR valve by washout sediments with active preparations leads to a partial and short-term improvement of its condition.

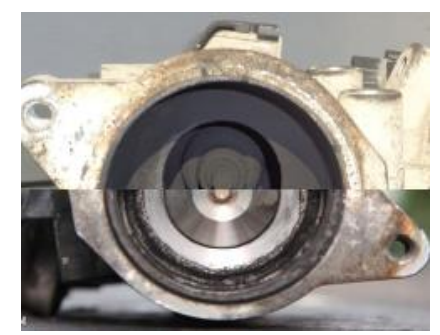

Fig. 3. Comparison of two pictures of EGR valve channels: channel with sediments (top picture), channel after partial removal of sediments with chemicals (bottom picture)

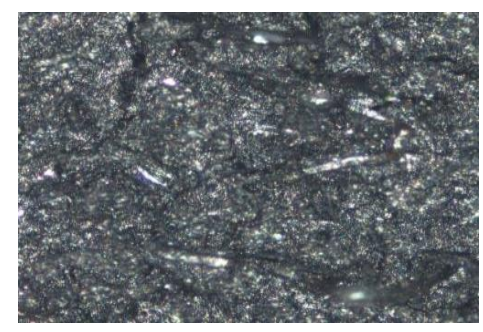

Fig. 4. Microscope image (magnification $100 \times$, reflected light) of the sediment on the outside the mushroom of valve EGR

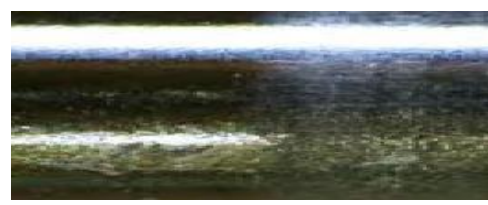

Fig. 5. Sediment on the bolt mushroom EGR valve in the co-operating zone with the guide sleeve.

On the bench for computer image analysis, a photo of the bolt mushroom EGR valve was made in the cooperation zone with the guide sleeve using a QImaging digital camera, Micro Publisher 5.0 RTV with a resolution of up to $2560 \times 1920$ pixels, with a linear polarizing filter. The Image Pro Plus 7.0 Media Cybernetics software was used to assessment of the percentage share of the area covered with sediment. After improving the quality of the obtained photo, the hi-pass filter $(7 \times 7)$ was transformed into black and white (image after quality improvement and black and white version) and then segmented (image after segmentation). Comparison of the share (black fields) in the area of the analysed sample showed the adhesion of sediments at the level of $61.4 \%$ of the bolt surface. In the sediment study process, spectral analyses were performed with a focus on identifying the chemical composition in order to determine the impact of the addition of biocomponents to diesel oil on the analysed process. The application included the evaluation of the content of precipitated non-oxidized organic components. The spectral analysis of sediments taken from the flue gas flow channel and the zone of the mushroom valve seat was carried out [11]. The infrared fluorescence spectrum (FTIR) was recorded with the FTS 175 produced by BIO-RAD (Fig. 6).

The band in the diagnostic area of $2000-900 \mathrm{~cm}^{-1}$ is also intensive, which indicates the presence of oxidation processes of organic compounds to carbonyl and carboxylic structures. The effects of these compounds on nitrogen oxides are related to the presence of hydrated carboxylic acid salts. The effect of these compounds on the nitrogen oxides is related to the presence of hydrated salts of carboxylic acids. The $1650 \mathrm{~cm}^{-1}$ band is derived from other compounds containing $\mathrm{C}-\mathrm{O}-\mathrm{NO}_{2}$ bonds, resulting from nitro-oxidation of engine oil components and fuel in contact with nitrogen oxides. The $1747 \mathrm{~cm}^{-1}$ band is visible due to the presence of degradation of FAME esters or di- and trimerization. For the purpose of identifying sediments of the ester group, the relations of carbonyl groups $\mathrm{C}=\mathrm{O}$ (aliphatic) with the corresponding band in the area of the wavenumber $1750-1735 \mathrm{~cm}^{-1}$ are representative. A band of about $1720 \mathrm{~cm}^{-1}$ is derived from other carbonyl or carboxylic compounds, while a band of about $1633 \mathrm{~cm}^{-1}$ indicates the presence of products of interaction of nitrogen oxides with fuel oxidation products. The $1620 \mathrm{~cm}^{-1}$ band is derived from other compounds containing C-O- $\mathrm{NO}_{2}$ bonds, resulting from nitro-oxidation of engine oil components and fuel in contact with nitrogen oxides. The weak $1735 \mathrm{~cm}^{-1}$ band is derived from other compounds containing $\mathrm{C}=\mathrm{O}$ bonds resulting from the oxidation of engine oil and fuel components. The observed intense $1735 \mathrm{~cm}^{-1}$ band is related to the presence of esters, for which the representative ones are the relations of $\mathrm{C}=\mathrm{O}$ (aliphatic) carbonyl groups with the bands in the $1750-1735 \mathrm{~cm}^{-1}$ range.

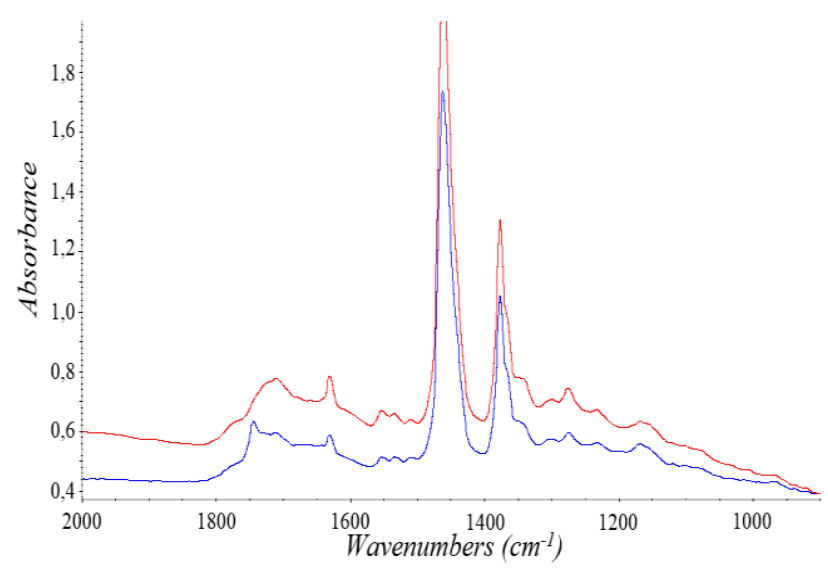

Fig. 6. Infrared spectrum (range $2000 \mathrm{~cm}^{-1}-900 \mathrm{~cm}^{-1}$ ) of a partial of soluble sediment taken from the flue gas duct (red) and the zone of the mushroom valve seat (blue)

The presence of ester structures are is also confirmed the bands in the area of "finger print" (ca. $1460 \mathrm{~cm}^{-1}$ and $1380 \mathrm{~cm}^{-1}$ ) [11].

Reducing the amount of sediment on work elements the use of a more effective detergent-dispersing additive package, thus guaranteeing the desired performance. Infrared 
spectroscopy analysis made after extraction of the sample showed clearly the proportion of organic compounds in the solid sludge. The main sources of sediment are the FAME polymer groups and components derived from various refining packages used for the production of biofuels.

\section{Conclusions}

1. The presented stages of testing and diagnostic inference in the case of multi-symptom states of motor failure along with a wide analysis of the recorded error codes, direct the procedure of inference to make the right diagnostic decision.

2. The main cause of the fault leading to the damage of the EGR valve turned out to be an excessive PM sediment in the zone of channels and mushroom valve in the EGR system.
3. Infrared spectroscopy analysis showed the proportion of organic compounds in the PM solid sediment. An analysis of fluorescence spectrum with the energy dispersion in relation to determining the proportion of sedimentary elements, together with the infrared recording of the spectroscopy spectrum showed the proportion of organic compounds in solid PM.

4. It is desirable to fully visualize the operating parameters of the interdependent systems and not to focus solely on the direct reading of the error codes indicated by the diagnostic tester.

\section{Acknowledgements}

This work was financed from the university's own resources.

\section{Nomenclature}

$\begin{array}{llll}\mathrm{CO} & \text { carbon monoxide } & \text { IDID } & \text { Internal Diesel Injector Deposits } \\ \mathrm{CO}_{2} & \text { carbon dioxide } & \text { MAF } & \text { Mass Air Flow } \\ \text { DOC } & \text { diesel oxidation catalyst } & \text { MIL } & \text { Malfunction Indicator Light } \\ \text { DPF } & \text { Diesel Particulate Filter } & \mathrm{NO}_{x} & \text { nitrogen oxides } \\ \text { EDC } & \text { Electronic Diesel Control } & \text { PM } & \text { Particulate Matter } \\ \text { EGR } & \text { Exhaust Gas Recirculation } & \text { OBDII } & \text { On-Board Diagnostic level 2 } \\ \text { FAME } & \text { Fatty Acid Methyl Esters } & \text { SCR } & \text { Selective Catalytic Reduction } \\ \text { HPCRS High Pressure Common Rail System } & \text { VTG } & \text { Variable Turbine Geometry }\end{array}$

\section{Bibliography}

[1] CAPROTTI, R., BREAKSPEAR, A. et al. Detergency requirements of future diesel injection system. SAE Technical Paper 2005-01-3901, 2005.

[2] CHŁOPEK, Z., SZCZEPAŃSKI, T. Research concept of the combustion engines properties in dynamic states. Combustion Engines. 2013, 154(3), 168-174.

[3] CIEŚLIKOWSKI, B., CYGNAR, M., JAKÓBIEC, J. Multifaceted diagnostic inference process for identifying the causes of self-ignition engine faults resulting from PM sediments. Combustion Engines. 2017, PTNSS-2017-C442.

[4] GUNTER, H. Common Rail - Systeme in der Werkstattpraxis, Technik, Prufung. Diagnose. Bad Worihofen. Krafthand Verlag Waltrer Schultz GmbH.

[5] HARTWICH, F. Can with flexible data-rate. Proceedings of the $13^{\text {th }}$ CAN Conference. Hambach Castle, Germany 2012.

[6] IDZIOR, M. et al. Analiza wpływu warunków eksploatacji na stan techniczny turbosprężarek doładowanych silników spalinowych. Logistyka. 2011, 3, 1129-1139.

[7] JAKÓBIEC, J., STANIK, W., MAZANEK, A. Olej napędowy wg. Światowej Karty Paliw - wydanie piąte wrzesień 2013. Logistyka. 2014, 3, 96-101.

Bogusław Cieślikowski, DSc., DEng. - Faculty in State University of Applied Sciences in Nowy Sacz, Poland.

e-mail: cibogdan@poczta.onet.pl
[8] MERKER, G., SCHWARZ, CH., TEICHMAN, R. Combustion engines development: mixture formation, combustion, emissions and simulation. Springer. 2012.

[9] MERKISZ, J., MAZUREK, S. Pokładowe systemy diagnostyczne pojazdów. Wyd. Komunikacji i Łączności. Warszawa 2007.

[10] MERKISZ, J., PIELECHA, J., BIELACZYC, P., WOODBURN, J. Analysis of emission factors in RDE tests as well as in NEDC and WLTC chassis dynamometer tests. SAE Technical Paper 2016-01-0980, 2016.

[11] SADLE, J. Spektroskopia molekularna. Wydawnictwa Naukowo Techniczne. Warszawa 2002.

[12] STANIK, W., JAKÓBIEC, J., WĄDRZYK, M. Wpływ stabilności termooksydacyjnej biokomponentów na pracę układu wysokociśnieniowego wtrysku paliwa typu Common Rail. Logistyka. 2015, 5, 569-576.

[13] WĘGIEL, S. Zasilanie silników HDI. Poradnik serwisowy nr 4. Instalator Polski 2004.

[14] WHITE, C., RANDALL, M. Kody usterek. WKiE. Warszawa 2008.

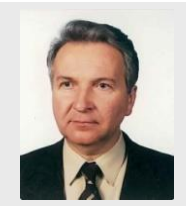

Mariusz Cygnar, DSc., DEng. - Faculty in State University of Applied Sciences in Nowy Sacz, Poland. e-mail: mcygnar@pwsz-ns.edu.pl 